\title{
European Association of Nuclear Medicine: adapt the present, shape the future
}

\author{
Savvas Frangos • Wolfram H. Knapp • on behalf of the \\ EANM Executive Committee
}

Published online: 24 January 2014

(C) EANM 2014

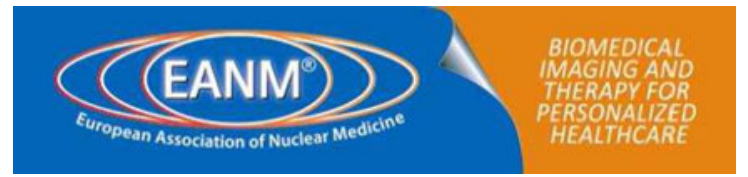

The European Association of Nuclear Medicine was born on 6 September 1985 after "a difficult but exciting delivery", as Professor Peter Ell described it in the book Nuclear Medicine: Fusing the Ideas of Democritus and Hippocrates - 25 Years of the EANM. Since this delivery, EANM has grown up to become one of the most powerful scientific organizations in the field of biomedical imaging and therapy, with highly professional executive organs and office. In parallel with this evolution, the medical field has changed, and thereby also the position of nuclear medicine within medicine. The EANM Executive Committee is committed to implementing within the Association those changes required to adapt to the evolving scenario that characterizes the medical field.

EANM Executive Committee members: Fred Verzijlbergen, Room Na602, Erasmus MC Central Location, CA Rotterdam, Netherlands; Arturo Chiti, Medicina Nucleare, Istituto Clinico Humanitas, Rozzano MI, Italy; Savvas Frangos, Nuclear Medicine Department, Bank of Cyprus Oncology Center, Strovolos, Nicosia, Cyprus; Jure Fettich, Department for Nuclear Medicine Radiopharmacy and Clinical Biochemistry, University Medical Centre Ljubljana, Ljubljana, Slovenia; Bernd Joachim Krause, Klinik und Poliklinik für Nuklearmedizin, Universitätsklinikum Rostock, Rostock, Germany; Dominique Le Guludec, Service de Médecine Nucléaire, Hopital Bichat, Paris, France; Wim Oyen, Department of Nuclear Medicine (756), Radboud University Medical Centre, Nijmegen, Netherlands

W. H. Knapp $(\triangle)$

International Neuroscience Institute, Hanover, Germany

e-mail: info@knapp-wh.de

S. Frangos

Nuclear Medicine Department, Bank of Cyprus Oncology Center,

Strovolos, Nicosia, Cyprus

Priorities have been identified and action plans put in place to achieve this goal. Among the various priorities, radiopharmaceutical availability, demonstration of clinical evidence of nuclear medicine procedures and education are considered the most important. It has also been decided that partnerships with other scientific societies, industry and patients' organizations should be strengthened. These partnerships will enhance the influence of EANM in the medical field, highlighting the usefulness of nuclear medicine diagnostic and therapeutic procedures to the ultimate benefit of patients.

Several actions are being coordinated by the EANM Executive Committee to deliver tangible results to the nuclear medicine community. In particular, at the Annual Congress of the EANM in Lyon, the Association put forward two major proposals designed to foster its development: an extension of its name with the phrase "Biomedical Imaging and Therapy for Personalised Healthcare" and a thorough revision of the Bylaws and Rules. Both the Delegates' and the Members' Assemblies approved with very large majorities the new "Statutes" that will replace the Bylaws and Rules from 1 January 2014. This revision was prepared by a Constitution Committee mandated by the Executive Committee for formal and strategic reasons. Formal reasons were, for example, redundancies in the Bylaws and Rules and descriptions of functions that were no longer adequate (such as "Task Group Coordinator"). Strategic considerations included, for example, the growing role of education, which is now one of the most important activities of the EANM. The current Bylaws do not mention the European School of Nuclear Medicine (ESNM), nor do they specify the role of the Dean. Another important strategic aim is to make the EANM Congress the leading event in our field worldwide, which requires continuity in planning of the scientific and educational content. All this has been taken into account in the drawing up of the new Statutes. 
Despite the adaptation to the new priorities, the spirit of the EANM, as originally embodied by the founders, the members of the Society of Nuclear Medicine - Europe and the European Nuclear Medicine Society, has not changed. The Association will continue to be governed by the member states (via delegates) and by the individual members. Although an efficient working board is required for a highly professional organization, the new Statutes adhere to the bottom-up principle wherever it makes sense, e.g. in proposing candidates for leading positions.

The following is a concise description of the major changes to the EANM regulations in the new Statutes:

- Name of document: "Statutes" will contain all regulations, as the separation between Bylaws and Rules did not prove useful. Specific regulations, such as those on the work of committees or on the Congress organization, have been laid down in "Instructions".

- Objective and Means: The definition of our field is an important part of the document. It has been adapted to reflect the developments during the past 25 years.

- Role of Organs: For each organ there is now an introductory paragraph defining the role of the organ for the Association.

- Renaming and job descriptions: "Executive Committee" is a rather unusual term in the context of scientific societies. In addition, there is frequently some confusion regarding "Executive Committee" and "Executive Secretariat". Therefore, we proposed to change the names to "Board" and "Executive Office", respectively.

The new Statutes give each Board member a precise job description. The composition of the Board is as follows:

- The merged position of "Treasurer/Secretary" is created. With increased professionalization of the Executive Office, the roles of both the Secretary and the Treasurer have become predominantly supervision of the operational work of the Executive Office. These functions are now combined and entail the obligation of close interaction with the Executive Office. The merger of the two positions is legally possible according to the Austrian Law of Associations (Vereinsgesetz 2002).

- The "Task Group Coordinator" is renamed "Committee Coordinator", as the term Task Group is considered no longer appropriate. Instead the Board will have the possibility of creating Task Forces for special or ad hoc assignments.

- The position of "Education Chair" is created. This reflects the increased importance of education in the strategy of the EANM.

- The new position of "Congress Chair" is created. With this innovation, two strategic decisions taken previously by the Executive Committee are taken into account. First, the EANM Congress is slowly but constantly growing (currently it has more than 5,000 participants) and it can be held in only a few select cities in Europe that fulfil the infrastructure requirements. Therefore, the Bylaws were changed in 2008 so that the President of Congress and the host country were decoupled, giving each country represented in the EANM the chance to propose one of its members as Congress President. Second, the strategic aim of further improving the quality of the Annual Congress implies continuity in respect of the positions responsible for the scientific content. Therefore, the position of Congress Chair has been created, with the Chair to be proposed by the Board and approved by the Delegates' and the Members' Assembly for a period of 3 years, renewable once. The possibility of holding the position of Congress Chair for 3 years, renewable once, was heavily contested in the Constitution Committee. It was this consideration that prompted the decision to impose the aforementioned high threshold of approval by both the Delegates' and the Members' Assembly (with approval of renewal to be preceded by a proposal supporting renewal from the Board).

- The function "Local Ambassador" is provided to give the host country of the Congress the opportunity to influence the Congress and to increase interaction with the local scientific community.

We appreciate that the amendments have been approved by a very large majority of members and delegates. We are confident that they will help to foster the further development of the Association and the future of nuclear medicine in Europe.

As mentioned above, another important decision was taken in Lyon. It was recognized that EANM has become a wellknown label and should not be changed. On the other hand, we felt that our official logo should point to a relevant benefit and programme for the future of our specialty. Therefore, it was decided to supplement the name of the Association with the phrase "Biomedical Imaging and Therapy for Personalised Medicine". We are aware that medicine has always been inherently "personal" in that care is oriented towards the needs of each patient. However, the term "personalised medicine" now commonly denotes the use of technology or procedures enabling a level of personalization that was previously not feasible or practical, and among the different medical specialties, nuclear medicine has extremely high potential to offer tools for individualization of therapeutic regimens, including radiotherapy or medication. It is hoped that by appending the above wording to the name of the EANM, the clinical reality and unique potential of our specialty will be rendered more visible.

The new Statutes of the EANM are available on the website: http://www.eanm.org/. 